\title{
Preparation of Activated Carbon From (Asphalt: Polymer) Mixtures and Improving its Adsorption Properties by Thermal Fusion Carbonization and Microwave Technique
}

\author{
Emad A.S. Al-Hyali ${ }^{*}$; Khalid A.O. AL-Memary²; Homam T. S. AL-Sayd Toohi \\ Department of Chemistry, College of Education of Pure Sciences, University of Mosul, Mosul, Iraq
}

Email: 1*emadabd2006@yahoo.com, ${ }^{2}$ kalid.a.waid73@uomosul.edu.iq, ${ }^{3}$ Homamchemistry@gmail.com

(Received January 15, 2019; Accepted February 27, 2019; Available online March 01, 2020)

DOI: 10.33899/edusj.2020.164375, (C) 2020, College of Education for Pure Science, University of Mosul.

This is an open access article under the CC BY 4.0 license (http://creativecommons.org/licenses/by/4.0/).

\begin{abstract}
:
Asphalt was modified by several methods including catalyzed treatment with a number of recycled polymers aiming at changing their chemical composition in order to be suitable for producing activated carbon, which is of great importance that is due to its uses in industry and in pollution control.

The best model in terms of asphaltene content was used in the preparation of activated carbon using excess amount of potassium hydroxide after atmospheric and vacuum distillation; complementing carbonization is then carried out. The selected activated carbon models were purified, and the activation process is finally achieved by employing microwave technique.

The properties of the synthesized models were tested by determining the adsorption capacity of iodine and methylene blue from aqueous media, the density, ash content and humidity. It is noticed that the chemical structure of the starting material and the use of both thermal fusion carbonization and the activation by microwave technique have great influences on the physical properties of synthesized carbon.
\end{abstract}

Keyword: Thermal Fusion Carbonization, Activated carbon, adsorption, Microwave Technique

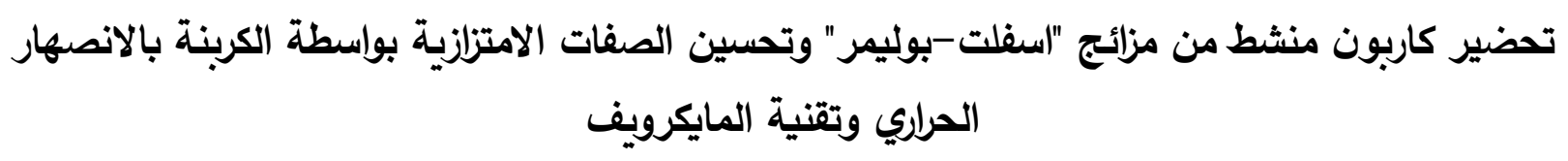

عماد عبد الاله صالح الحيالي1* و خالد احمد عويد المعماري2 و همام طه سلطان السيد توحي

قسم الكيمياء, كلية التربية للعلوم الصرفة, جامعة الموصل, الموصل, العراق

الخلاصة

حُور الإسـلت بعدة طرق اشتملت على المعالجة المحفزة مع عدد من المخلفات البوليمرية بهدف تحوير التركيب الكيميائي للإِففلت

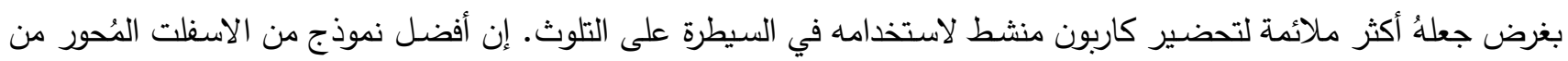

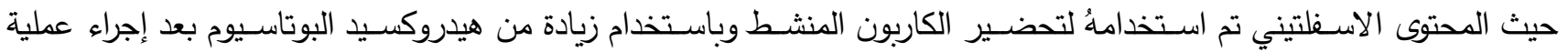




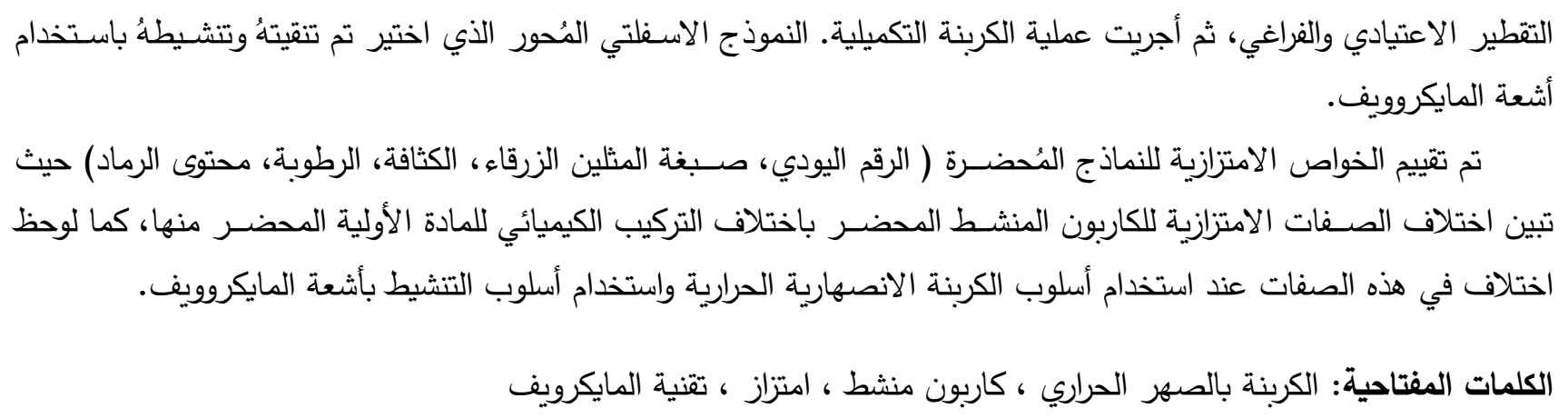

\section{Introduction}

The world recently faces hazardous problem of pollution which is due to the increase in its levels as a result of industrial evolutions and people activities.

This increase in levels of pollution makes it more risky and makes completion of substantial processing of treatment need more requirements [1].

Many studies are focusing on various ways to overcome the problem of pollution by taking advantage of some residue of industrial waste or contaminated plants. Some waste polymers, such as reclaimed tires rubber and polymethyl methacrylate, were converted into useful materials used with asphalt to modify asphalt rheological properties and produce asphalt of high asphalten contents. Then this modified asphalt were used to prepare activated carbon.

Activated carbon is widely used as adsorbent because of its properties (Highly adsorbent capacity for chemicals gases and liquids, porosity homogenous structure, high internal surface area) [2,3] .

AL-Taai [4] managed to prepare new types of activated carbon and tested its efficiency by adsorbing some dyes on it.

Muslim. et al [5] were studied the possibility of producing activated carbon from natural asphalt. The resulted activated carbon then mixed with waste condensation polymers (phenol formaldehyde).

\section{Experimental Part}

\section{1- Modification of Rheological Properties of Asphalt by reclaiming tires rubber and Polymethyl methacrylate Mixtures}

Asphalt was treated with amixture of reclaimed tires rubber and Polymethyl methacrylate in ratio (1:1) (polymer: polymer). The mixture was added to asphalt in range of (0.5-4)\% weight percentage with excess of $(0.5) \%$ weight in presence of $(0.06) \% \mathrm{AlCl}_{3}$ and (1)\%sulfur. They were mixed well and they were exposed to a temperature raised to $\left(180^{\circ} \mathrm{C}\right)$ for 30 minutes. The mixture was then placed in an oven microwave for different periods $(5,10,15)$ minutes at 360 watt.

The rheological properties (Ductility, Penetration, Softening Point, Penetration Index) were measured $[6,7,8]$.

\section{2- De- Asphalting}


$1 \mathrm{~g}$ of the modified asphalt sample was put in a flask. $40 \mathrm{ml}$ of petroleum ether $60-80^{\circ} \mathrm{C}$ was added to it at a ratio (1:40) (weight:volume). The solution was shaken in an electrical shaker for(3)hour at $\left(25^{\circ} \mathrm{C}\right)$. The asphaltene was then filtered, dried, weighed and the percentage of asphaltene was calculated for the studied samples [9].

\section{3- Starting Materials Used to Prepare the Activated Carbon}

The best model obtained in term of asphaltene content was submitted to the following distillation process [9].

\section{3-1 Atmospheric Distillation}

A sample of $(100 \mathrm{~g})$ was distilled at atmospheric pressure in order to remove the largest amount of light particles .

\section{3-2 Vacuum Distillation}

After the atmospheric distillation, the produced residual were distillated under low pressure $(20 \mathrm{mmHg})$ and the residue was used to prepare the activated carbon.

\section{4- Preparation of Activated Carbon}

\section{4-1 Primary Carbonization}

The residue of vacuum distillation was put in a pottery basin and mixed with potassium hydroxide in a ratio (1:2) (heavy residual: $\mathrm{KOH})$ at $350{ }^{\circ} \mathrm{C}$ for (3)hours .

\section{4-2 Final Carbonization}

The material produced from primary carbonization was heated to $(350,550,700){ }^{\circ} \mathrm{C}$ respectively for 2 hours.

\section{4-3 Purification of Activated Carbon}

In order to purify the prepared activated carbon, which is contaminated with alkaline and metallic components, the following treatment were performed:-

1- Washing by distilled water to get rid of metallic material.

2- The carbon was refluxed with $(10 \%) \mathrm{HCl}$ solution for 5hours to remove the ions and to reduce the metallic components[10].

3- Direct filtration is carried out for the hot solution.

4- The produced carbon was washed with distilled water several times till it becomes neutral.

5- It was dried in the oven at $120{ }^{\circ} \mathrm{C}$ for 24 hours, then crushed and separated using molecular sieves of $75 \mu \mathrm{m}$ mesh.

\section{4-4 Activation process by microwave radiation}


The best model of the prepared activated carbon in term of adsorption properties was reactivated using microwave technique where a certain quantity of a sample was put in a container then put in the microwave oven with power 720 watt at different periods $(5,10,15)$ minutes, after that the adsorption properties were estimated.

\section{5- Assessment of the efficiency of activated carbon}

\section{5-1 Measuring the Internal Surface Area of Activated Carbon}

It is normally carried out by estimation of adsorption capacity of carbon to adsorb iodine (mg/g) from its aqueous solution, This is one of the easier and faster way to estimate the internal surface area of the pores on surface of an adsorbent. (1g) of activated carbon was weighed and placed in a conical flask. $10 \mathrm{ml}$ of $5 \% \mathrm{HCl}$ was added to it and heated till it reached the boiling point for 30 minutes. The flask was cooled to room temperature, then $100 \mathrm{ml}$ of $0.1 \mathrm{~N}$ iodine solution was added. The flask contents were shacked using electrical shaker for 30 minutes then filtered. $50 \mathrm{ml}$ of the filtrate was titrated with $0.1 \mathrm{~N}$ sodium thiosulfate till the solution becomes pale yellow. Then $1 \mathrm{ml}$ of freshly prepared starch indicator is added. The titration was completed till the blue color of starch indicator was disappeared and the solution became colorless. The volume of the used thiosulphate was measured. The volume of adsorbed iodine was calculated using the following equation [11]:-

$\mathrm{X}=\mathrm{A}-[2.2 \mathrm{~B} \times \mathrm{mL}$ of Thiosulfate Used $] \ldots . .(1)$

$A=N_{1} \times 12693$

$\mathrm{B}=\mathrm{N}_{2} \times 126.93$

where:

$\mathrm{X}$ : the weight in $(\mathrm{mg})$ of adsorbed iodine by $(1 \mathrm{~g})$ of activated carbon.

$\mathrm{N}_{1}$ : the normal concentration of iodine solution $(0.1 \mathrm{~N})$.

$\mathrm{N}_{2}$ : the normal concentration of sodium thiosulphate $(0.1 \mathrm{~N})$.

The iodine number was calculated using the following equation:-

$$
\text { In }=\frac{X}{M} D
$$

where:

M: the Wight of the used activated carbon.

D: correction factor.

\section{5-2 Measurement of the External Surface Area of Activated Carbon By Adsorption of Methylene Blue (mg/g) from Aqueous Solution}

This method involve putting (0.1g) of activated carbon in a conical flask. A known amount of methylene blue dye (20ppm) was added to the flask then it was shacked for 24 hours at room temperature. When the color disappeared an additional amount of the dye solution should be added till the color never disappeared. 
The absorbance of the clear solution of dye was measured at wavelength of $(665 \mathrm{~nm})$. The concentration of the remained dye in its aqueous solution was calculated by calibration curve.

\section{5-3 Density Measurement}

A specific amount of activated carbon was placed to fill a pre-weight $5 \mathrm{ml}$ density flask, which is empty, and then filled and weighed with activated carbon. The density was calculated according to the following equation[12] .

$$
\operatorname{Density}\left(\mathrm{g} / \mathrm{cm}^{3}\right)=\text { mass } / \text { volume }
$$

\section{5-4 Measuring of Ash Content percentage}

One gram of activated carbon was put in a pottery basin in an electrical oven at $1000^{\circ} \mathrm{C}$ for (3)hours then the sample was cooled and weighed. The percentage of Ash content was measured from the difference in weights [13].

\section{5-5 Determination of Humidity Percentage}

In an electrical oven, one gram of activated carbon was heated at $150{ }^{\circ} \mathrm{C}$ for 3 hours, then it weighed and from the weight difference the percentage of humidity was measured [14].

\section{Results and Discussion}

\section{The preparation of activated carbon including several approaches:}

\section{The Modification of Asphalt by the treatment with polymeric mixtures:}

Modification treatment of Asphalt is performed by using polymeric mixtures (reclaimed tires rubber and Polymethyl methacrylate) which mixed in (1:1) (polymer:polymer) at different percentages as described in the experimental part, in order to increase the attachment between the polymer and the condensed aromatic rings in asphalt molecules. This might lead to an increase in the alkyle part and change in its chemical structure. The rheological properties (Ductility, Penetration, Softening Point, Penetration Index) $[6,7,8]$ are calculated as a measure of the change in the chemical structure of asphaltic material. The results obtained were listed in Table (1). 
Table(1): The rheological properties of asphalt modified by different percentages of reclaim tires rubber and Polymethyl methacrylate in presence of $0.06 \%\left(\mathrm{AlCl}_{3}\right)$ and $1 \%$ of sulphur at power 360 watt at different times.

\begin{tabular}{|c|c|c|c|c|c|c|c|}
\hline 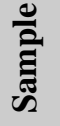 & $\begin{array}{l}\text { Time } \\
(\mathbf{m i n})\end{array}$ & $\begin{array}{c}\text { RTR+PMMA } \\
(w \mathrm{w} \%)\end{array}$ & $\begin{array}{l}\text { Ductility } \\
\left(25^{\circ} \mathrm{C}, \mathrm{cm}\right)\end{array}$ & $\begin{array}{l}\text { Penetration } \\
\left(25^{\circ} \mathrm{C}, \mathrm{mm}\right)\end{array}$ & $\begin{array}{l}\text { Softening } \\
\text { Point }\left({ }^{\circ} \mathrm{C}\right)\end{array}$ & $\begin{array}{l}\text { Penetration } \\
\text { Index }\end{array}$ & $\begin{array}{c}\text { Asphalten } \\
(\%)\end{array}$ \\
\hline A & 0 & 0 & +100 & 40.0 & 55.0 & -0.531 & 36.0 \\
\hline 1 & 5 & 1.0 & 67.0 & 37.0 & 75.0 & 2.849 & 53.0 \\
\hline 2 & 10 & 1.0 & 35.5 & 34.0 & 69.0 & 2.832 & 49.0 \\
\hline 3 & 15 & 1.0 & 48.0 & 32.0 & 65.0 & 0.919 & 48.5 \\
\hline 4 & 5 & 1.5 & 43.0 & 33.0 & 58.0 & -0.316 & 48.0 \\
\hline 5 & 10 & 1.5 & 33.0 & 31.0 & 60.0 & -0.055 & 49.0 \\
\hline 6 & 15 & 1.5 & 35.0 & 30.0 & 58.0 & -0.508 & 53.0 \\
\hline 7 & 5 & 2.0 & 56.0 & 31.0 & 56.0 & 1.150 & 50.0 \\
\hline 8 & 10 & 2.0 & 43.0 & 30.0 & 62.0 & 0.250 & 56.0 \\
\hline 9 & 15 & 2.0 & 50.0 & 20.5 & 59.0 & -1.020 & 49.0 \\
\hline 10 & 5 & 2.5 & 40.0 & 30.0 & 56.0 & -0.910 & 49.9 \\
\hline 11 & 10 & 2.5 & 48.0 & 32.0 & 52.0 & -1.640 & 50.0 \\
\hline 12 & 15 & 2.5 & 55.2 & 30.0 & 50.0 & -2.211 & 53.0 \\
\hline 13 & 5 & 3.0 & 39.0 & 29.0 & 55.0 & -1.180 & 41.0 \\
\hline 14 & 10 & 3.0 & 42.0 & 31.0 & 53.0 & -0.055 & 47.0 \\
\hline 15 & 15 & 3.0 & 50.0 & 33.0 & 34.0 & -1.143 & 52.0 \\
\hline 16 & 5 & 3.5 & 35.0 & 26.0 & 58.0 & -0.760 & 58.0 \\
\hline 17 & 10 & 3.5 & 25.0 & 30.0 & 60.0 & -0.910 & 55.6 \\
\hline 18 & 15 & 3.5 & 39.0 & 28.0 & 56.0 & -1.040 & 60.0 \\
\hline 19 & 5 & 4.0 & $\begin{array}{l}34.0 \\
\end{array}$ & 25.0 & 60.0 & -0.477 & 51.2 \\
\hline 20 & 10 & 4.0 & 31.0 & 28.0 & 62.0 & 0.110 & 50.0 \\
\hline 21 & 15 & 4.0 & 30.0 & 26.0 & 66.0 & 0.658 & 48.0 \\
\hline
\end{tabular}

RTR: Reclaim Tires Rubber.

PMMA: Polymethyl methacrylate.

Table (1) shows that, the Modification treatment of Asphalt by using polymeric mixtures leads to an increase in Softening Point while the value of Penetration and ductility is decreased when compared with non modified asphalt. The asphalten content is also increased as the ratio of polymeric mixture is increased till it reaches $3.5 \%$ where asphalten content reached $60 \%$. This gave an indication that the functional groups in polymeric mixtures begin to react and grow to give a high asphalten content. This means that the increase in molecular weight of asphalt is due to the binding of a high molecular weight polymeric molecules with asphaltic compounds through a chemical reactions.

And to make sure that the $60 \%$ of asphalten content whichs obtained from the sample (18) is not a precipitate material, the melting point of this content is compared to that of the asphalten obtained from the original sample (A). The two melting points were found to be very consistent. They were $\left(200^{\circ} \mathrm{C}\right)$ for original sample (A) and $\left(204^{\circ} \mathrm{C}\right)$ for the modified asphalt. This results proved that, the obtained percentage is asphalten and the rheological properties of asphalt is improved. This indicated by the enhancement of the results of rheologic measurement (Ductility, Penetration, Softening Point, Penetration Index) $[6,7,8]$. The modified asphaltic model with the highest asphalten content (model 18) could be used as a base starting material in the preparation of the activated carbon, due to the fact that, a high asphalten content leads to an increase in the yield of the prepared activated carbon. This gives an industrial and commercial preference. Also the presence of polymers leads to enhance the quality of inner and external pores of activated carbon and to develop the porous structure. 


\section{Thermal fusion carbonization:}

After the process of atmospheric and vacuums distillation on the modified asphaltic (model 18), it was then carbonized by using excess of $\mathrm{KOH}(1: 2)$ (heavy residual: $\mathrm{KOH}$ ) at $350^{\circ} \mathrm{C}$ for three hours. The produced material from primary carbonization was heated to $\left(350,550\right.$ and $\left.700{ }^{\circ} \mathrm{C}\right)$ respectively for two hours in order to complete the activation process. The activated carbon was purified according to the pargraphs (4-3) in the experimental part. The efficiencies of activated carbon models were tested in terms of (Iodine number, Methylene Blue, Density, Ash content, Humidity Content). The results obtained are listed in Table (2).

Table(2): The properties of the prepared activated carbon compared with commercial model .

\begin{tabular}{|c|c|c|c|c|c|c|}
\hline Samples & TempC & $\begin{array}{c}\text { Iodine } \\
\text { number } \\
(\mathbf{m g} / \mathbf{g})\end{array}$ & $\begin{array}{c}\text { Methylene } \\
\text { Blue } \\
(\mathbf{m g} / \mathbf{g})\end{array}$ & $\begin{array}{c}\text { Density } \\
\left(\mathbf{g} / \mathbf{c m}^{\mathbf{3}}\right)\end{array}$ & $\begin{array}{c}\text { Ash } \\
\text { content } \\
\mathbf{\%}\end{array}$ & $\begin{array}{c}\text { Humidity } \\
\text { Content } \\
\mathbf{\%}\end{array}$ \\
\hline $\mathbf{C}^{*}{ }^{*}$ & --- & 180.8 & 35.0 & 0.616 & 1.000 & 1.010 \\
\hline $\mathbf{C}_{\mathbf{1}}$ & 350 & 432.1 & 88.0 & 0.554 & 1.000 & 1.100 \\
\hline $\mathbf{C}_{\mathbf{2}}$ & 550 & 572.0 & 150.0 & 0.400 & 1.200 & 1.102 \\
\hline $\mathbf{C}_{3}$ & 700 & 991.0 & 230.0 & 0.257 & 1.225 & 1.103 \\
\hline $\begin{array}{c}\mathbf{C}^{\text {*** }} \\
\text { B.D.H }\end{array}$ & --- & 908 & 90.0 & 0.345 & 3.200 & 0.800 \\
\hline
\end{tabular}

Co*: Activated carbon prepared from the residual of vacuum distillation of asphalt without any additienal material. $\mathrm{C}^{* * *}:[15]$.

Table (2) indicates that, the adsorption capacities of activated carbon, prepared from the asphaltic model modified by polymeric mixture to adsorb the methylene blue dye and Iodine, show a great developing in the adsorption properties when compared to the non modified asphalt.

An increase in the density values is also noticed which shows that, this way of treatment can be used to produce activated carbon with a high quality toward small particle adsorption. Besides the carbonization method which also plays an important role in the development of adsorption properties and abilities for producing carbonic material, it is also noticed that the increase in temperature in the range (350-700 $\left.{ }^{\circ} \mathrm{C}\right)$ leads to development in the adsorption properties .

At high temperature the base $(\mathrm{KOH})$ plays an impartant role in activation. The presence of hydroxide ion in $\mathrm{KOH}$ is regarded as a significant factor in activation process which is working on developing the minute pore structure for the primary material used in the activated carbon production. The gradual heating to $350{ }^{\circ} \mathrm{C}$ for 3 hours in carbonization is to make the base $(\mathrm{KOH})$ reach its melting point so it can be mixed completely with vacuum distillation residual. Completing the heating to $\left(350,550,700{ }^{\circ} \mathrm{C}\right)$ for 2 hours is then achieved. This process is completely carried out in a different way from the carbonization method used in other studies. In this study the carbonization was done in an electrical furnace tightly closed with the presence of small holes for the liberation of gases while other studies the carbonization methods are performed in an open steel container and at a very high temperature that could reach to $\left(550^{\circ} \mathrm{C}\right)$ or more where the sample could burn at this temperature. The presence of atmospheric $\left(\mathrm{O}_{2}\right)$ helps the burning which may give high percentage of Ash.

The ratio of the added base(1:2) (heavy residual: $\mathrm{KOH}$ ) is chosen according to previous studies[4,16], since the use of a higher ratio will cause damage to a larger part of the formed pores on the surface of the prepared activated carbon. It can also noticed that, the of contained ash was low due to using the refluxed heat process with $10 \% \mathrm{HCl}$ solution which helps to get rid of the biggest part of the metallic components found in starting material or that produced from the preparation of activated carbon [10] .

The values of densities were also low, these proved that the models are of a high porosity, since the density is inversely proportional to the number of pores found in the material. 
From the above it can be concluded that, model(C3) is the best model in terms of adsorption properties such as(Iodine number, Methylene Blue) beside the values of humidity, density and ash content.

\section{The activation process using microwave technique:}

The prepared activated carbon (model C3) of the best adsorption properties is additionally reactivated using microwave technique as in paragraphs (4-4) in the experimental part. A certain quantity of the sample is placed in a container and then put in a microwave oven under a power (720watt) at different time $(10,20,30)$. The previous tests (the adsorption capacities of methylene blue ,iodine humidity, density and ash content) were repeated on the obtained sample, in order to determine the development occurred on the carbon properties efficiency as an adsorbent. The results obtained were listed in Table(3).

Table (3): The properties of prepared activated carbon which is obtained by using microwave technique at power(720watt) at different time.

\begin{tabular}{|c|c|c|c|c|c|c|}
\hline Samples & $\begin{array}{c}\text { Time } \\
(\mathbf{m i n})\end{array}$ & $\begin{array}{c}\text { Iodine } \\
\text { number } \\
(\mathbf{m g} / \mathbf{g})\end{array}$ & $\begin{array}{c}\text { Methylene } \\
\text { Blue } \\
(\mathbf{m g} / \mathbf{g})\end{array}$ & $\begin{array}{c}\text { Density } \\
\left(\mathbf{g} / \mathbf{c m}^{\mathbf{3}}\right)\end{array}$ & $\begin{array}{c}\text { Ash } \\
\text { content } \\
\mathbf{\%}\end{array}$ & $\begin{array}{c}\text { Humidity } \\
\text { Content } \\
\mathbf{\%}\end{array}$ \\
\hline $\mathbf{C}_{\mathbf{4}}$ & 10 & 1018.0 & 250.0 & 0.257 & 1.225 & 1.101 \\
\hline $\mathbf{C}_{5}$ & 20 & 1074.0 & 259.0 & 0.255 & 1.250 & 1.100 \\
\hline $\mathbf{C}_{\mathbf{6}}$ & 30 & 1130.8 & 300.0 & 0.250 & 1.500 & 1.000 \\
\hline $\begin{array}{c}\text { C } \\
\text { B.D.H }\end{array}$ & --- & 908 & 90.0 & 0.345 & 3.200 & 0.800 \\
\hline
\end{tabular}

The results in Table(3) show that the use of microwave technique at power(720watt) leads to a great development in the porous structure. This is can be concluded from the increasing in iodine number and the adsorption capacity of methylene blue when compared with the value obtained in Table (3) The highest obtained value was at period 30 minute (modelC 6 ), The choice of microwave power(720watt) for activation was based on previous studies[17]. All the values of humidity and Ash content of prepared models were in allowable limits to be found in the activated carbon which is much lower than that found in commercial models of activated carbon.

The reason of the choice of microwave technique is due to its features that give it out of the presence of other techniques. The microwave waves penetrate the surface of the material and interact with each single molecule in the model exposed to the radiation. The heat generated inside the material is resulted from cold waves and its quantity depending mainly on the nature of materials.

The microwave technique is also not a time consuming and it can reduce the activation period from hours to minutes and saving cost. It is also a clean technology and does not require a solvent.

Finally its clear that the variation in the chemical composition of starting material has an obvious effect on the adsorption ability of prepared activated carbon. It is also found that the way of carbonization plays an important role in the development of the efficiency and proprieties of the produced activated carbon.

An important finding can be concluded in this study is that, the rubber residues which are considered as source of pollution and from a burden on the environment are converted into activated carbon with properties surpass than the commercial carbon which can be used as an adsorbent and it can help in controlling pollution. It also can be a source of the national income. 


\section{References}

1. Chigondo, F; Nyamunda, B. C; Sithole, S. C. and Gwatidzo, L., 5:43-50,(2013).

2. Thomas B. and George. S., 1: 1-5, (2015).

3. Ramadhan O and Hamdon A., 31: 377-382,(2008).

4. Al-Taey S.I., Ph.D. Thesis, College of Education of pure Sciences, University of Mosul,(2017).

5. Muslim, R. F; Rabeea, M. A; Zaidan, T. A;. ISSN:0974360X (2019).

6. ASTM D5-97, "Standard test method for penetration of bituminous materials",Section 4,Vol .04 .03, Road and paving materials-vehicle-pavement systems ,New york,Ny.

7. ASTM D113-99, "Standard test method for ductility of bituminous materials",Section 4,Vol .04 .03, Road and paving materials-vehicle-pavement systems , New york, Ny.

8. ASTM D36-95]Reapproved 2000 [, "Standard test method for softening point of bituminous materials(Ring and Ball Apparatus)",Section 4,Vol .04.

9. Ali, L. H. and Al-Ghannam, K. A., , J. Fuel, 60: 1043-1046, (1981).

10. Mahajan, O. and Walker, P. L., Fuel, . 58:333-337, (1979).

11. Awwa standard for Granular activated carbon, B604-74, Sec.7, Approved by J.The American water works association board of directors on Jan.28, (1974).

12. ASTM D2854, Standard Test Method for Apparent Density of Activated Carbon. part 30. New York, NY, (1996).

13. ASTM D2866, Total Ash Content of Activated Carbon . part 30. New York, NY . ASTM D2867, (1983) Standard Test Method for Moisture in Activated carbon . part 30. New York, NY, (1994).

14. ASTM D2867, Standard Test Method for Moisture in Activated carbon . part 30. New York, NY, (1983).

15. Y.S. Ho, G. McKay, "The kinetics of sorption of divalent metal ions onto sphagnum moss peat", water Res. 34: 735-742, (2000).

16. Owaid K.A and Homady A., Journal of education and science., 26:202,(2016).

17. Owaid K.A; Thanon A.A; Ali M.M., Journal of education and science 26: 24 (2013). 